\title{
Çeşitli Japon Bıldırcını Hatlarının Arilesteraz Tipleri Bakımından Karşılaştırılması
}

\author{
Mehmet Ali YILDIZ
}

Ensar BAŞPINAR 1

Geliş Tarihi: 02.02.1998

\begin{abstract}
Özet: Çalışılan 4 farklı japon bıldırını hattında arilesteraz tipleri belirlenmiş ve EsA ${ }^{+}$fenotiplerinin frekansları yüksek bulunmuştur. Bıldırcın populasyonlarının karşılaştııılmasında arilesteraz sisteminin etkin bir şekilde kullanılabileceği sonucuna varılmışıı.
\end{abstract}

Anahtar Kelimeler: Japon bıldırcını, Arilesteraz.

\section{Comparison of Different Japanese Quail Lines Based on Arylesterase Types}

\begin{abstract}
In this study arylesterase types were determined and $\mathrm{ESA}^{+}$phenotypes were high in four different japanese quail lines. Arylesterase system also can be used for comparison of quail populations.
\end{abstract}

Key Words: Japanese quail, Arylesterase.

\section{Giriş}

Çeşitli kanatı türleriyle karşılaştırıldığında japon bıldırcınlarında tesbit edilen mutasyon ve major varyantlara ilişkin bilinenler oldukça sınırlı ve yetersiz seviyededir. Bunun nedeni yapılan çalışmaların hemen tamamında bıldırcının model hayvan olarak kullanılmış olması gösterilebilir.

Moleküler biyolojide meydana gelen yeni gelişmelere paralel olarak kalitatif karakterler üzerinde çalışılması amacıyla bir çok modern araç ve metot geliştirilmiştir. Uygulama alanına sokulan yeni yöntemlerle bilgi toplamadaki vasıtaların artması, japon bıldırcınlarının çeşitli boyutlarda tanımlanmasına ve belirli özelliklerin tesbit edildiği yeni hatların geliştirilmesine yardımcı olmaktadır (Crawford 1990).

Koyunlarda rutin analizlerde çok yaygın olarak kullanılan arilesteraz (EsA) sistemi, $(x$-naftil asetatı hidrolize etme yeteneğine göre iki tipe ayrilabilmekte ve $\alpha$-naftil asetata karşı aktivitesi yüksek olan $\mathrm{EsA}^{+}$, düşük olanı ise EsA olarak tanımlanmaktadır (Tucker ve ark. 1967).

Arilesteraz polimorfizminin bıldırcınlarda da kullanılabilirliğine ilişkin literatürde sadece bir yayına rastlanımıştır (Asal ve Yıldız 1997). Söz konusu araştırmada, çalışılan 8 farklı japon bıldırcını hattında, $E_{s A}{ }^{+}$fenotiplerinin nisbi miktarının yüksek olduğu, bu fenotiplerin EsA sistemi bakımından tam bir polimorfizm gösterdiği ve populasyonların karşılaştırılmalarında bu sistemin de etkin bir şekilde kullanılabileceği ifade edilmektedir.

EsA sisteminde olduğu gibi, yüksek-düşük, var-yok, negatif-pozitif, evet-hayır, doğru-yanlış, ölü-canlı vb. şekilde ifade edilen ve 1 ve/veya 0 olarak kodlanan özelliklere ikili (binary) özellik, bu karakterlerin sayısal kodlarına da ikili veri adı verilmektedir.

Bu çalışmada 4 farklı japon bıldırcını hattı, ikili veri özelliğine sahip arilesteraz sistemi bakımından karşılaştırılmıştır.

\section{Materyal ve Yöntem}

Araştırma, Ankara Üniv. Zir. Fak., Zootekni Bölümü, Bıldırcın Yetiştiriciliği Ünitesi'ndeki Avrupa orijinli siyah (S), kahverengi $(K)$ ve kırmızı gözlü beyaz $(B)$ genotip grupları ile japon orijinli beyaz (W) tüy rengine sahip bıldırcın hatlarında yürütülmüştür. Avrupa orijinli hatların ( $S, K$ ve $B$ ) tüy rengini belirleyen genler bakımından genetik analizleri yapılmamakla birlikte, bu hatlar 8 generasyon kendi içlerinde akrabalı yetiştirilmiş ve tüy rengi bakımından herhangi bir fenotipik açılma meydana gelmemiştir. Çalışmada kullanılan Japon orijinli beyaz (W) bıldırcın hattı, 1994 yılında Gifu Üniversitesi'nden getirtilmiştir. Bu genotip grubunda tüy renginin beyaz oluşunu sağlayan otozomal gen $(\mathrm{W})$, yabani alleline $\left(\mathrm{W}^{+}\right)$eksik dominant (incomplete dominance) etkilidir (Wakasugi ve Kondo 1973)

Arilesteraz analizleri plazma örneklerinde tüp testi (Tucker ve ark. 1967) yöntemine göre yapılmıştır. Bu amaçla; kan örnekleri 3 ml'lik antikuagulantlı (EDTA) şırıngalar ile doğrudan kalpten alınmıştır. Alınan kan örnekleri Laboratuvara getirilerek 3000 dev/dak.'da 15 dakika santrifüj edilmiş, plazma ve hücre kısmı birbirinden ayrılmıştır. Bir cam üzerine önce bir damla kadar plazma örneği ve bunun üzerine de iki damla aktivite boya çözeltisi (Asetonda çözülmüş \% $1^{\prime}$ lik ( $x$-naftil asetat solusyonundan 1 $\mathrm{ml} ; 0.05 \mathrm{ml}$ Fast Blue BB tuzu ve $49 \mathrm{ml}$. destile su) ilave edilmiștir. Bir kaç saniye içerisinde $\mathrm{ESA}^{+}$(1: arilesteraz aktivitesi yüksek) fenotipleri sarımsı-kahverengi bir renk verirken, $\mathrm{ESA}^{-}$(0: arilesteraz aktivitesi düşük) fenotipleri ise boyandıktan yaklaşık 30 saniye sonra koyu-yeşile dönen bir renge dönüşmektedir.

Genotip grupları arasında arilesteraz aktivitesi bakımından bir fark yoktur" hipotezi Cochran Q-testi ile test edilmiştir (Sokal ve Rohlf 1995). Bu amaçla STATISTICA for windows paket programında yer alan $Q$ testi kullanılmıştır. Farklı genotip gruplarının belirlenmesinde Hamerle (1978)'nin önerdiği ve Hecker ve Birgitt (1994) tarafından bildirilen yöntem kullanılmıştır (Başpınar 1996).

\footnotetext{
Ankara Üniv. Ziraat Fak. Zootekni Bölümü Biyometri ve Genetik Anabilim Dalı - Ankara
} 


\section{Bulgular ve Tartışma}

Arilesteraz fenotiplerinin genotip gruplarına göre dağılımı Çizelge 1 'de verilmiştir. Incelenen populasyonların tamamında $\mathrm{EsA}^{+}$fenotiplerinin nisbi frekansı yüksek bulunmuştur. Bu sonuç, Asal ve Yıldız (1997) tarafından yapılan çalışma ile paralellik göstermektedir.

"Genotip grupları arasında arilesteraz aktivitesi bakımından bir faklılık yoktur" hipotezi Cochan Q-testi ile test edilmiş ve red edilmiştir $(Q=15.82 ; S D=3 ; P<0.01)$.

Arilesteraz aktivitesi bakımından gruplar arasındaki farkların $\% 5$ ve $\% 1$ seviyelerinde önemli olabilmesi için, sırasıyla en az 4.79 ve 5.82 birim olması gerekmektedir (Hamerle 1978; Hecker ve Birgitt 1994; Pearson ve Hartley 1966).

Buna göre EsA sistemi bakımından Avrupa orijinli hatlar $(S, K$ ve $B)$ arasındaki farklar istatistiki olarak önemli bulunmamıştır. Ancak Japon orijinli genotip grubu(W) ile Avrupa orijinli populasyonlar arasındaki farklar istatistik olarak önemlidir (Çizelge 2).

Bu sonuçlardan hareketle, Asal ve Yıldız (1997) tarafından da belirtildiği gibi, bıldırcın populasyonlarının karşılaştırılmasında arilesteraz sisteminden de yaralanılabileceği ileri sürülebilir.

Çizelge 1. Arilesteraz fenotiplerinin genotip gruplarına dağılımı

\begin{tabular}{|l|c|c|c|c|}
\hline \multirow{2}{*}{$\begin{array}{l}\text { Arilesteraz } \\
\text { Fenotipleri }\end{array}$} & \multicolumn{4}{|c|}{ Genotip Grupları } \\
\cline { 2 - 5 } & $\begin{array}{c}\text { Siyah } \\
(\mathrm{S})\end{array}$ & $\begin{array}{c}\text { Kahverengi } \\
\text { (K) }\end{array}$ & $\begin{array}{c}\text { Kırmızı } \\
\text { Gözlü } \\
\text { Beyaz } \\
(\mathrm{B})\end{array}$ & $\begin{array}{c}\text { Beyaz } \\
(\mathrm{W})\end{array}$ \\
\hline ESA $^{+}(1)$ & 11 & 10 & 9 & 16 \\
\hline EsA $^{-}(0)$ & 6 & 7 & 8 & 1 \\
\hline
\end{tabular}

Çizelge 2. EsA ${ }^{+}$fenotipleri bakımından genotip grupları arasındaki farklar ve bunların önem kontrolleri

\begin{tabular}{|l|c|c|c|}
\hline & $\begin{array}{c}\text { Kahverengi } \\
(\mathrm{K})\end{array}$ & $\begin{array}{c}\text { Kırmızı } \\
\text { Gözlü } \\
\text { Beyaz } \\
(\mathrm{B})\end{array}$ & $\begin{array}{c}\text { Beyaz } \\
(\mathrm{W})\end{array}$ \\
\hline Siyah (S) & 1 & 2 & $5^{*}$ \\
\hline Kahverengi (K) & - & 1 & $6^{\star *}$ \\
\hline $\begin{array}{l}\text { Kırmızı Gözlü Beyaz } \\
(\mathrm{B})\end{array}$ & - & - & $7^{\text {** }}$ \\
\hline
\end{tabular}

$$
{ }^{*} \mathrm{P}<0.05 ;{ }^{* *} \mathrm{P}<0.01
$$

\section{Kaynaklar}

Asal, S. ve M.A. Yıldız, 1997. Çeşitli Japon Bıldırcını (Coturnix japonica) Hatlarında Protein Polimorfizmi ile Bunların Verimle Olan ilişkileri. TÜBITAK (Proje No: VHAG-1198).

Başpınar, E., 1996. Var-Yok Şeklinde ifade Edilebilen Özellikler Bakımından Çeşitli Grupların Karşılaştırılması. Kükem Dergisi, 20: 77-83.

Crawford, R.D., 1990. Poultry Breeding and Genetics. Chapter 1. Origin And History Of Poultry Species. R.D. Crawford ed. Elsevier, Amstedam, pp:: 1-42.

Hamerle, A., 1978. A Note On Multiple Comparisons For Randomized Complete Bloks With A Binary Respons. Biom. J., 20 (718): 743-748.

Hecker, H. and W. Birgitt, 1994. A Mixed Model for Binary Data: The Modified $\chi^{2}$-Test. Biom. J., 30(8): 783-799.

Pearson, E.S., and H.D. Hartley, 1966. Biometrica Tables For Staticians. Vol, 1: 3rd Ed. University Press, Cambridge.

Sokal, R.R., and F. Rohlf, 1995. Biometry. Third Edition, W.H. Freeman and Company, New York.

STATISTICA for windows pc. 5.0, 1995. Stat Soft, Inc. 2325 East 13th Street, U.S.A.

Tucker, E.M., Y. Suzuki, and C. Stormont, 1967. Three New Phenotypic Systems In The Blood Of Sheep. Vox Sang, 13: 246-262.

Wakasugi, N., and K. Kondo, 1973. Breeding Methods For Maintenance Of Mutant Gene And Establishment of Strains In Japanese Quail. Exp. Animals, 22 (Suppl.): 151 159. 